Prepared for the National Aeronautics and Space Administration

\title{
Geologic Map of the Aeolis Dorsa Region, Mars
}

By Devon M. Burr, Robert E. Jacobsen, Alexandra Lefort, Rose M. Borden, and Samantha E. Peel

Pamphlet to accompany

Scientific Investigations Map 3480

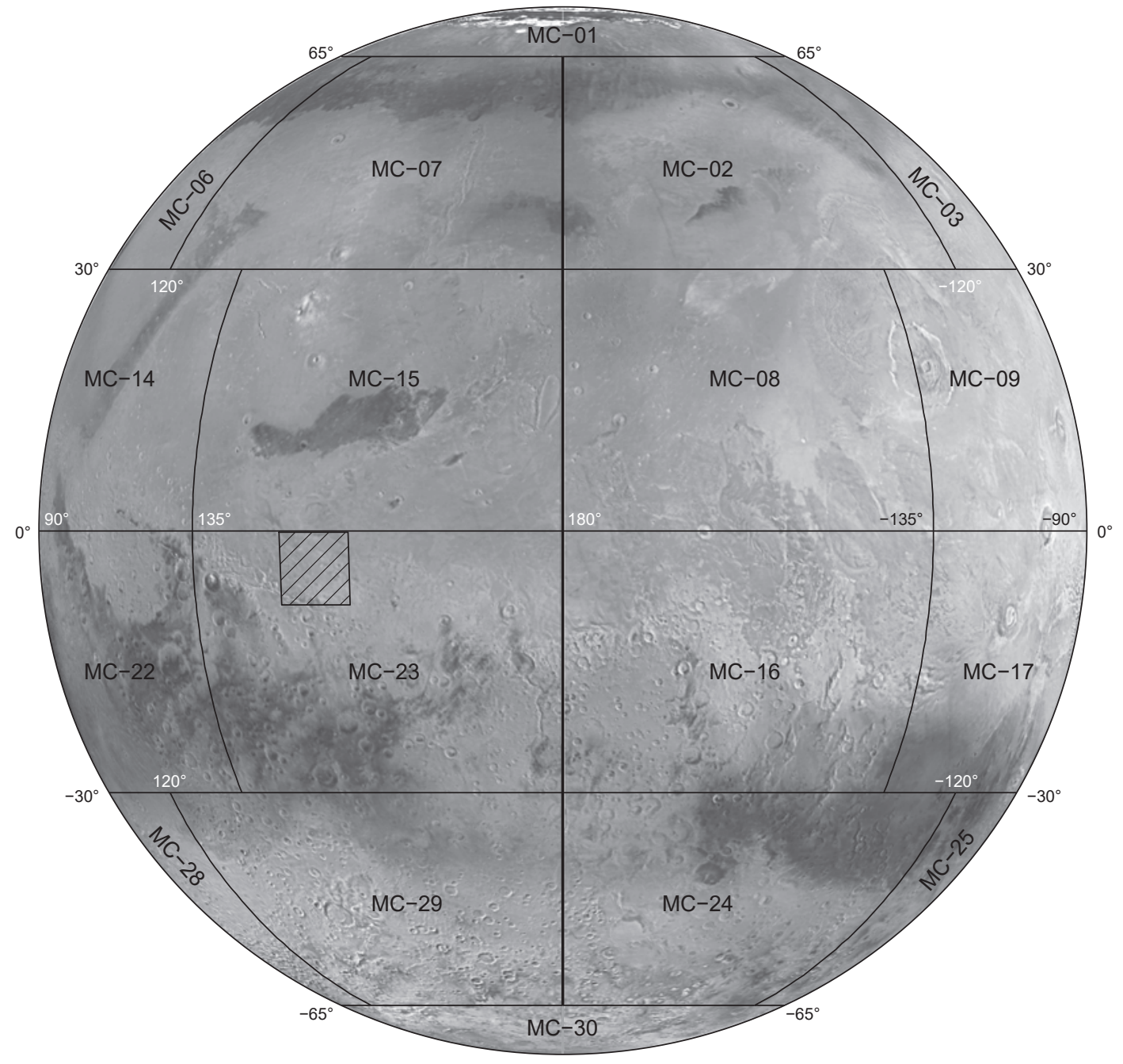

2021

U.S. Department of the Interior

U.S. Geological Survey 


\section{U.S. Geological Survey, Reston, Virginia: 2021}

For more information on the USGS — the Federal source for science about the Earth, its natural and living resources, natural hazards, and the environment-visit https://www.usgs.gov or call 1-888-ASK-USGS.

For an overview of USGS information products, including maps, imagery, and publications, visit https://store.usgs.gov.

Any use of trade, firm, or product names is for descriptive purposes only and does not imply endorsement by the U.S. Government.

Although this information product, for the most part, is in the public domain, it also may contain copyrighted materials as noted in the text. Permission to reproduce copyrighted items must be secured from the copyright owner.

Suggested citation:

Burr, D.M., Jacobsen, R.E., Lefort, A., Borden, R.M., and Peel, S.E., 2021, Geologic map of the Aeolis Dorsa region, Mars: U.S. Geological Survey Scientific Investigations Map 3480, 1 sheet, scale 1:500,000, pamphlet 11 p., https://doi.org/10.3133/sim3480.

ISSN 2329-1311 (print)

ISSN 2329-132X (online)

Cover. Map showing the location of the Aeolis Dorsa region, Mars (hachured rectangle) and major physiographic features. Image is Mars Orbiter Laser Altimeter artificial shaded relief overlain on Thermal Emission Imaging System daytime infrared mosaic. Orthographic projection centered at long $180^{\circ} \mathrm{E}$. 


\section{Contents}

Introduction

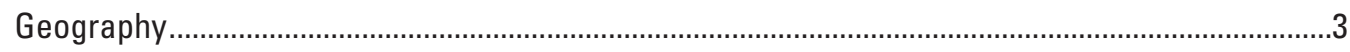

Base Map and Data

Methodology

Unit Groups, Names, and Labels ....................................................................................

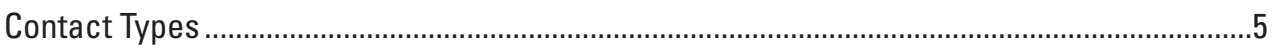

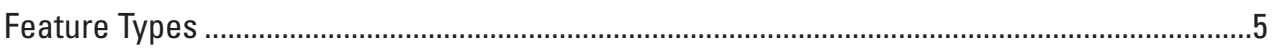

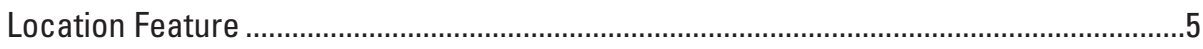

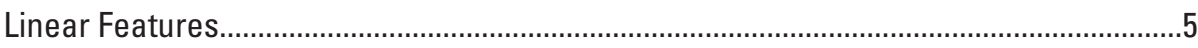

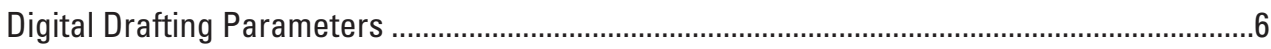

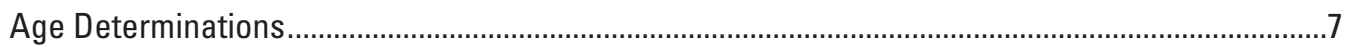

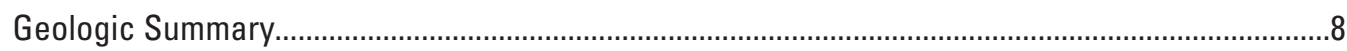

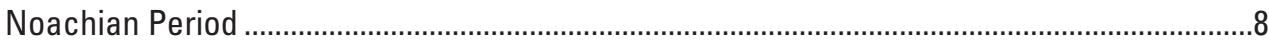

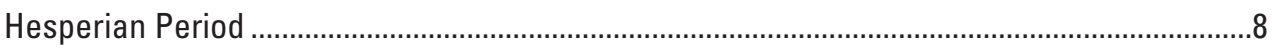

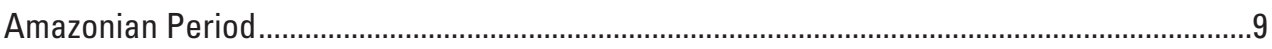

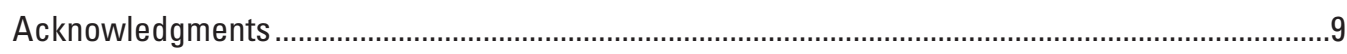

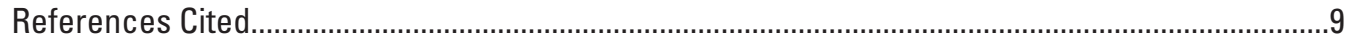

\section{Figures}

1. Map of the Aeolis Dorsa region using colorized Mars Orbiter Laser Altimeter topography overlain on Context Camera (CTX) imagery and mosaic of Thermal Emission Imaging System daytime infrared data to fill in areas without CTX data coverage map sheet

2. Context Camera unblended mosaic images showing examples of a wrinkle ridge and a sinuous ridge. map sheet

3. Context Camera unblended mosaic illustrating crosscutting relations between the three plana units $\left(\mathrm{Hp}_{1}, \mathrm{AHp}_{2^{\prime}}\right.$ and $\left.\mathrm{AHp}_{\mathrm{u}}\right)$ map sheet

4. Context Camera unblended mosaic illustrating the crosscutting relations for the two lowest Aeolis Dorsa units, $\left(\mathrm{Had}_{1}\right.$ and $\left.\mathrm{Had}_{2}\right)$. map sheet

5. Context Camera blended mosaic and Thermal Emission Imaging System nighttime infrared mosaic showing an example of the coincidence in tone between the visible and thermal data observed in some areas of the undivided Aeolis Dorsa Unit..... map sheet

6. Context Camera unequalized mosaic showing stratigraphic windows into the lower Aeolis Dorsa unit. map sheet 


\title{
Geologic Map of the Aeolis Dorsa Region, Mars
}

\author{
By Devon M. Burr, ${ }^{1,2}$ Robert E. Jacobsen, ${ }^{2}$ Alexandra Lefort, ${ }^{2}$ Rose M. Borden, ${ }^{2}$ and Samantha E. Peel ${ }^{2}$
}

\section{Introduction}

The dichotomy boundary on Mars is a global topographic and physiographic region that marks the change from the southern highlands to the northern lowlands (Irwin and Watters, 2010; Tanaka and others, 2014). This boundary commonly consists of transitional units of eroded and deposited sedimentary materials and volcanic lithologies (Tanaka and others, 2014). These sedimentary units, which are variable in expression, record the geologic and climatic changes that occurred over the duration of their formation. In some locations, the dichotomy boundary contains evidence for past fluvial runoff from the highland to the lowlands (Di Achille and Hynek, 2010). Other locations show the influence of aeolian abrasion (Ward, 1979; Mandt and others, 2008, 2009; Zimbelman and Griffin, 2010). In addition to these two dominant extrinsic processes, the terrain along the dichotomy boundary contains evidence for collapse (Skinner and Tanaka, 2018), tectonic deformation (McGill and Dimitriou, 1990), and volcanism (Hartmann and Berman, 2000).

A series of transitional units, formerly denoted in aggregate as the Medusae Fossae Formation (MFF; Tanaka and others, 2005), extends from south of Elysium Mons (approximate long $140^{\circ}$ E.) along the southern margin of the Cerberus plains to south of Amazonis Planitia (approximate long $220^{\circ}$ E.). Initial crater counts in Viking Orbiter data yielded an Amazonian age (Tanaka, 1986). Subsequent studies using higher resolution data derived an older (Hesperian) age of emplacement on the basis of crater counts and investigations of relative age relationships (Kerber and Head, 2010: Zimbelman and Scheidt, 2012).

Aeolis Dorsa, a population of sinuous ridges, are located in the MFF transitional units between the cratered southern highlands and the northern lowlands. These ridges are concentrated between lat $-10.30^{\circ} \mathrm{N}$., long $148.60^{\circ} \mathrm{E}$., and lat $-8.130^{\circ} \mathrm{N}$., long $156.520^{\circ} \mathrm{E}$., as per the definition of the Aeolis Dorsa in the Gazetteer of Planetary Nomenclature (https://planetarynames.wr.usgs.gov), although examples of the same morphology are found outside of this area (figure 8 of Burr and others, 2009). The Aeolis Dorsa region, used here to designate the area surrounding this concentration of sinuous ridges, consists of a large sedimentary basin bounded by two high-standing plana to the east and west (fig. 1), the southern highland to the south, and the Cerberus Palus to the north.

The Aeolis Dorsa region comprises most of the westernmost and stratigraphically lowest part of the MFF and contains evidence for all significant dichotomy processes - fluvial, aeolian, tectonic, and volcanic - providing an extensive and multifaceted geologic record consistent with the extensive age duration of the region. The Aeolis Dorsa are interpreted to be inverted fluvial deposits (Jacobsen and Burr, 2017, and references therein). The low stratigraphic position of these deposits (Jacobsen and Burr, 2017) and the time required for their formation (Kite and others, 2015 b) suggest a most likely formation age of Late Noachian to Early Hesperian (Burr and others, 2016), consistent with the age of fluvial units elsewhere on Mars (Tanaka and others, 2014). The superposed deposits modified by extensive aeolian scour (Kite and others, 2015a; Jacobsen and Burr, 2017) likely represent processes that occurred during the Amazonian Period (Burr and others, 2016). Thus, we suggest the Aeolis Dorsa region contains geologic units (Burr and others, 2019) that represent the global transition from the wetter Noachian to the more arid Amazonian (Carr and Head, 2010, and references therein). This paleoclimatic transition is reflected in the regional geomorphology. Local and regional stratigraphic analyses show that older units were emplaced by fluvial processes (Kite and others, 2015a; Jacobsen and Burr, 2017), which might have been controlled by a downstream water body and include deltaic deposits (Cardenas and others, 2017; Hughes and others, 2019). These fluvial and (or) deltaic units sometimes appear to be overlain by thin units of potential fluvial origin, which would indicate a decrease in depositional activity on the basis of their narrower plan form and geospatially restricted distribution (Kite and others, 2015a; Jacobsen and Burr, 2017). In other locations, this fluvial and (or) deltaic unit is superposed by a unit of scattered distributary deposits, hypothesized to be alluvial fans (Jacobsen and Burr, 2017) or in one location by another hypothesized deltaic deposit (DiBiase and others, 2013). Later, nonfluvial units were emplaced and eroded by aeolian processes indicated by the extensive yardangs - irregular or lemniscate ridges formed by abrasion of windblown sand (Ward, 1979, Zimbelman and Griffin, 2010).

\footnotetext{
${ }^{1}$ Northern Arizona University

${ }^{2}$ University of Tennessee, Knoxville
} 
The Aeolis Dorsa region has been of interest chiefly because of these extensive fluvial deposits (Burr and others, 2009, 2010; Lefort and others, 2012, 2015; DiBiase and others, 2013; Williams and others, 2013; Kite and others, 2015a, 2015b; Jacobsen and Burr, 2016, 2017; Cardenas and others, 2017; Hughes and others, 2019), exposed by pervasive aeolian erosion. Aeolian erosional morphologies, such as yardangs, were apparent in Viking Orbiter images (Ward, 1979), but recent, higher resolution data have revealed and enabled the characterization of these now-exposed water-lain deposits. In the central $\mathrm{MFF}$ region (long $170^{\circ}$ to $190^{\circ} \mathrm{E}$ ), Harrison and others (2013) suggested that a sinuous ridge network is aqueous in origin and resulted from groundwater flow. In comparison, the Aeolis Dorsa region offers hundreds of such water-lain sinuous ridge networks or individual features having a variety of morphologies and relative stratigraphic positions (for example, Burr and others, 2009, 2010; DiBiase and others, 2013; Williams and others, 2013; Kite and others, 2015b; Cardenas and others, 2017; Jacobsen and Burr, 2017; Hughes and others, 2019).

This substantial record of varied fluvial activity is located about 750 kilometers $(\mathrm{km})$ to the east-northeast of Gale crater, the landing site of the Mars Science Laboratory (MSL) rover (Grotzinger and others, 2012). This proximity both provides in-place contextual data for interpreting the geology of Aeolis Dorsa and makes interpretation of units therein relevant to the MSL mission. Study of the Aeolis Dorsa region also provides context for the Interior Exploration using Seismic Investigations, Geodesy and Heat Transport (InSight) mission to Mars to study the planet interior through seismometry, thermometry, and radio science (Banerdt and Russell, 2017; Banerdt and others, 2018). The InSight mission landed in Elysium Planitia, about $950 \mathrm{~km}$ to the west-northwest of the center of the Aeolis Dorsa map area.

Consequently, a more complete understanding of the range of geologic and geomorphologic processes that sculpted this area of the highland-lowland transition-including the processes that operated during the Late Noachian to Amazonian transition - is needed. Regional coverage in highresolution images, combined with topographic data, add to this understanding through more detailed geologic observations and resultant interpretations of Aeolis Dorsa, as presented in this map (lat $0.0^{\circ} \mathrm{N}$., long $147.5^{\circ} \mathrm{E}$. to lat $-8.0^{\circ} \mathrm{N}$., long $156.0^{\circ} \mathrm{E}$.).

This work builds on previous mapping of this region, which was first mapped as part of the Aeolis quadrangle (MC-23) by Scott and Carr (1978) from Mariner 9 images at 1:5,000,000 scale. Scott and Carr (1978) described the Aeolis Dorsa map area as constituting a rolling plains unit "Hpr" that consists of smooth undulating surfaces with low to moderate crater density, lobate scarps, wrinkle ridges, and mottled appearance in places. This morphology was interpreted as lava flows that postdate the highlands. This unit is superposed by a plains unit "Apc" that shows the underlying topography that Scott and Carr (1978, pl. 1) interpreted as "Lava plains covered with a discontinuous veneer of eolian deposits...." A plateau unit in the southern part of the Aeolis Dorsa map area and a scattered knobby unit are also mapped; the latter was interpreted as erosional remnants of the former.
Subsequently, the inclusion of the Aeolis Dorsa region in the 1:15,000,000 scale global geologic map series (Greeley and Guest, 1987) was based on Viking Orbiter images. Units that crop out within the Aeolis Dorsa map area include the lower and middle members of the MFF, which show smooth to rough, eroded surfaces that were interpreted as lava flows with interleaved pyroclastic deposits. A knobby plains material (unit "Apk" of Greeley and Guest, 1987) was mapped between the two high-standing MFF plana (Aeolis and Zephyria Plana) and was interpreted as an erosional remnant of uncertain origin. The surrounding material to the north in the Aeolis Dorsa map region is Cerberus plains material, which was interpreted by Greeley and Guest (1987) as younger channel and floodplain material (unit "Achu”).

The Elysium Planitia, whose southern border abuts the Aeolis Dorsa region north of the equator, is also mapped on the basis of Viking Orbiter images at 1:5,000,00 scale (Tanaka and others, 1992). Elysium map units that are contiguous with Aeolis Dorsa units include the same lower MFF member as the geologic map of the eastern equatorial region by Greeley and Guest (1987). The Cerberus plains material in contact with the high-standing MFF plana, characterized by unit "Ache" of Tanaka and others (1992, pl. 1) as "smooth, dark to mottled ... [with] flow patterns..." and crosscutting channels, were interpreted as "extensive, thin alluvial deposits... [with] young lava flows."

The northern plains, an area contiguous with the north border of the Aeolis Dorsa region, was mapped using image data from the Mars Global Surveyor (MGS) and Mars Odyssey (ODY) at 1:15,000,000 scale (Tanaka and others, 2005). Contiguous units include the MFF, characterized by unit "Aam" of Tanaka and others $(2005$, pl. 1) as a "vast, discontinuous deposit along [the] south border of Elysium and Amazonis Planitiae... made up of...layers, some of which exhibit systems of parallel linear ridges and grooves .... rimless pits and mesas" were interpreted as Amazonian wind-sculpted ash deposits. The surrounding Elysium province units (for example, unit " $\mathrm{AEc}_{3}$ " of Tanaka and others, 2005, pl. 1), characterized by "flat-lying, broad flows with lobate margins... marked by ridges that outline plates," were interpreted as lava flows.

The 1:20,000,000 scale global geologic map of Mars by Tanaka and others (2014), which was based on image and topographic data from MGS, ODY, Mars Express (MEX), and Mars Reconnaissance Orbiter (MRO), identifies the Aeolis Dorsa map region as composed almost entirely of transitional units. The Amazonian and Hesperian transitional undivided unit "AHtu" of Tanaka and others $(2014$, pl. 1) constitutes the former MFF and is characterized by "irregularly shaped plateaus ... [with] dense linear ridges, grooves, and scarps hundreds of meters wide and tens of kilometer long..."; they interpreted the unit as eolian and (or) pyroclastic air-fall deposits with yardangs. Subdued and pedestal craters and wrinkle ridges also characterize these units. Along the greatest elevation change in the south, the Hesperian and Noachian transition unit "HNt" of Tanaka and others $(2014, \mathrm{pl} .1)$ is described as "knobs, mesas, and intervening aprons and plains" that are interpreted as tectonically contracted impact sediments and volcanic deposits. North of the equator on the global map 
(that is, north of the Aeolis Dorsa region) are Amazonian volcanic units. In the Cerberus plains immediately north and northeast of the map area, these planar units are interpreted as flood lavas, whereas on the Elysium Mons edifice farther to the north, they are characterized as stacked, sloping materials and interpreted as "lava and perhaps volcaniclastic flows." A small outcrop mapped as a Late Hesperian transition unit (unit "lHt" of Tanaka and others, 2014, pl. 1), characterized by plainsforming deposits of "sedimentary materials and volcanic rocks" crops out in the northeast corner of the Aeolis Dorsa map area.

The extensive geologic history revealed in the Aeolis Dorsa region by aeolian erosion provides an opportunity to better understand the processes that occurred along the boundary between the highlands and lowlands during the climatic transition from the Late Noachian and Early Hesperian Epochs to the Amazonian Period. Numerous topical investigations of the regional geology have demonstrated the importance of evidence from this region for understanding paleoclimate on Mars (as indicated by references above). However, in order to access this information, the stratal and geomorphic complexity requires geologic mapping to synthesize these deposits, along with tectonic, collapse, volcanic, and potentially lacustrine landforms, into a coherent history. Herein, we delineate, discriminate, and describe the geologic and stratigraphic units of the Aeolis Dorsa region, including small areas of the southern highlands and low-lying lava plains to the north. The result is an evolutionary history that provides insight into both the climatic transition on Mars and the geologic processes that occurred along this section of the dichotomy boundary.

\section{Geography}

We selected the map region to focus on the inverted fluvial deposits, which are concentrated around the interior margins of the two high-standing MFF plana, Aeolis Planum to the west and Zephyria Planum to the east (fig. 1). Between these two plana is a broad (about 150-200-km wide), relatively flat interplana trough oriented southeast-northwest, parallel to the orientation of the plana. The approximate centerline of this trough contains the longest inverted fluvial deposit on Mars, the Aeolis Serpens, which is anomalous both for its length of several hundred kilometers within the map area-extending beyond the map area to the north (Williams and others, 2013) and for its central location. The interplana trough is bordered to the south by terrain of comparable elevation to the Aeolis and Zephyria plana, which forms a U-shaped area of lower elevation. Aeolis Chaos, an elongate depression in the southcentral area of the map, is as much as about $1 \mathrm{~km}$ lower in elevation than its surroundings and is oriented west-northwest to east-southeast, parallel to the adjacent dichotomy boundary. The southwestern corner of the map consists of southern highlands terrain. This map area, extending from lat $-8^{\circ} \mathrm{N}$. to the equator between long $147.5^{\circ} \mathrm{E}$. and $156^{\circ} \mathrm{E}$., covers a total area of about 230,000 square kilometers $\left(\mathrm{km}^{2}\right)$. Named craters within the area are Asau (25.05 km diameter), Kalba (14.15 km diameter), Neves (22.13 km diameter), and Obock (14.45 km diameter).

\section{Base Map and Data}

The base map establishes the consistent and salient characteristics of each geologic unit. As a result, the base should cover the map area at a resolution necessary to discern and distinguish features at the size of a minimum mappable unit. For this map, the minimum mappable unit is about $1 \mathrm{~km}^{2}$. Photogeology and geomorphology have provided the foundation for planetary geologic mapping (Greeley and Batson, 1990) and did so for this work. The base map of this mapping effort comprises optical images from the MRO Context Camera (CTX; Malin and others, 2007). CTX images cover about 99.5 percent of the map area at a resolution of approximately 6 meters $(\mathrm{m})$ per pixel, allowing discrimination of features as small as about $12-18 \mathrm{~m}$ in diameter, and their extensive global coverage supports comparison of the Aeolis Dorsa mapped units to landscapes and features elsewhere on Mars. Mapping was accomplished on this set of individual CTX images provided by the U.S. Geological Survey (USGS) Planetary Geologic Map Coordination Group, which were not blended in order to preserve the full dynamic range of each image.

Other, nonvisible-wavelength datasets can provide corroborative and (or) complementary information to the base map. To corroborate mapping on the CTX base map, discern smaller or non-optical features, and determine crosscutting relations, we used several additional datasets. Topographic datasets assisted in delineating units and in deriving relative age by providing absolute and relative elevations. The MGS-borne Mars Orbiter Laser Altimeter (MOLA; Smith and others, 2001) provided regional topographic data as a digital elevation model (DEM) with 128 pixels per degree (about $463 \mathrm{~m}$ per pixel) interpolated from $300-\mathrm{m}$ footprint surface altimetry measurements. Local topographic data included DEMs created using Ames Stereo Pipeline (Beyer and others, 2018, and references therein) from CTX-stereo pair images. In addition to CTX data, higher resolution (about $0.25 \mathrm{~m}$ per pixel) images from the MRO High Resolution Imaging Science Experiment (HiRISE; McEwen and others, 2007) were used to discern relative stratigraphic relations (for example, crosscutting and embayment) and to corroborate unit differentiation and delineation with additional characteristics. Lastly, non-optical imaging data, specifically, day- and nighttime infrared data from the ODY Thermal Emission Imaging System (THEMIS; Christensen and others, 2004), compiled into a 100-m-per-pixel mosaic by the USGS Astrogeology Science Center, were used locally to correlate and map unit contacts on the basis of similar thermal properties. Observations in these secondary datasets (Fergason and others, 2013; Fergason and Weller, 2018) supported the derivation of the accompanying Correlation of Map Units and additional characteristics in the Description of Map Units sections.

Before our mapping was completed, personnel from the Bruce Murray Laboratory at the California Institute of Technology (Caltech) created a global, blended CTX mosaic of Mars (Dickson and others, 2018). This blended mosaic minimizes or eliminates seams between individual CTX images and so was selected as the base for the publication of this map owing to its improved appearance. However, a geospatial offset exists between the unblended CTX mosaic on which the mapping was performed and the blended CTX mosaic from Caltech. Thus, the mapping was adjusted to the Caltech mosaic via a three-step process. 
Both the original USGS and Caltech CTX mosaics were created using spacecraft pointing to project the CTX images onto the surface. This uncontrolled pointing results in random alignment errors between the CTX mosaics and well-controlled base maps, that is, between the MOLA (Smith and others, 2001) and USGS THEMIS (Christensen and others, 2004) controlled mosaics (Fergason and others, 2013; Fergason and Weller, 2018). The CTX mosaics were warped using ArcMap georefencing tools to better align to the THEMIS base map, and 32 control points with a statistically robust and consistent distribution over the mapping area were manually placed between the CTX mosaic and THEMIS-controlled mosaic using small impact craters or knobs to align the Caltech CTX mosaic to the THEMIS IR-controlled mosaic. We applied the projective transformation method (Moffitt and Mikhail, 1980) available in ArcMap, which resulted in a Root Mean Square (RMS) error of $110.4 \mathrm{~m}$. For context, this error is approximately one THEMIS IR mosaic pixel or one-fifth of a millimeter at map scale. We then applied the same method to align the USGS-created CTX mosaic to the transformed (or warped) Caltech mosaic. We manually placed 34 control points between the two CTX mosaics and applied the same projective transformation method, resulting in a $60.4 \mathrm{~m}$ RMS error. Lastly, we used the control points vectors derived from the warping of the USGS CTX mosaic to the Caltech CTX mosaic to warp the layers mapped on the USGS CTX mosaic to the Caltech mosaic.

\section{Methodology}

Our mapping methodology follows approaches outlined by Tanaka and others (2005) for the hemisphere-scale geologic map of the northern plains of Mars and in the Planetary Geologic Mapping Protocol (Skinner and other, 2018). Below, we describe unit groups, names, and symbols; types of geologic contacts; types of feature symbols; and digital drafting parameters used to create the Aeolis Dorsa map.

\section{Unit Groups, Names, and Labels}

We defined 19 geologic units and 6 unit groups in the Aeolis Dorsa map as shown in the Correlation of Map Units section. Geologic units were defined on the basis of their characteristic morphologies and (or) landforms, thermal properties, and geographic and (or) stratigraphic relationships to one another. The units and unit groups were generally named using generic morphologic and (or) geographic identifiers to avoid genetic connotations and preserve objectivity (Tanaka and others, 2005). The exception is the naming of the crater unit (AHc), crater fill unit (Hcf), and crater units group, which is consistent with previously published USGS geologic maps of Mars (Tanaka and others, 2005).

For the highlands and transitional unit groups, we followed the physiographic divisions provided in previous maps, especially the global geologic map of Mars by Tanaka and others (2014). We described a group of three highlands units. In the southwest corner of the map area, the highlands plateau unit (Nhp) composes high-standing, steep-sided massifs consisting of degraded larger craters, numerous smaller craters, and wide linear troughs. Also mapped are the highlands undivided unit $\left(\mathrm{HNh}_{\mathrm{u}}\right)$, which includes the plateau massif slopes, and the highlands mesas unit (HNhm), in the south-central map area adjacent to the plateau unit, which consists of blocky upper surfaces having a lower crater density and bounded by steep slopes.

After the global geologic map of Mars of Tanaka and others (2014), we identified a group of three transitional units, although we use a more localized definition of transitional compared to the global map in delineating these units. On the global map, transitional units are "occupying highland/ lowland marginal zones and dissected areas of highland terrain" and, including the MFF plana and dissected highland massifs, encompass most of the Aeolis Dorsa map area (Tanaka and others 2014, pl. 1). At this regional scale, we use transitional to refer to terrain that is intermediate geospatially and in elevation between the highlands units and the plana and Aeolis Dorsa units. Adjacent to some outcrops of highlands units, the transitional terrain unit (HNtt) forms a rough surface of mesas, scarps and irregular ridges. Adjacent to and eastward of this transitional terrain, we mapped an undivided transitional unit $\left(\mathrm{Ht}_{\mathrm{u}}\right)$ of smooth to finely lineated surfaces. North of the highlands units is the Aeolis Chaos depression, centered at lat $-7.13^{\circ} \mathrm{N}$., long $150.6^{\circ} \mathrm{E}$. This depression includes some highlands mesas units that exhibit a blocky landscape about 500 to $1,000 \mathrm{~m}$ lower in elevation than the surrounding terrain, whose outline is approximated by the $-2,200$-m-elevation contour. We mapped this depression as a chaos terrain unit (Htct) within the transitional units group.

Other unit groups are named relative to geography. The plana units group makes up the Aeolis and Zephyria Plana, as well as similar-textured terrain within the highland troughs. The plana mesas unit (Npm) located on Aeolis Planum is characterized by small outcrops of high-standing terrain, some with rectilinear edges in plan view. A cratered plains unit (Hpc), which composes planar landscapes with wrinkle ridges and high densities of small (less than 1-km-diameter) craters, is located at low elevations in the northwestern and northeastern parts of the map area and is morphologically similar to and (or) contiguous off the map area with global volcanic and transitional units (for example, "lHt," "AHv," and "lAv" from Tanaka and others, 2014). The remaining three units in this group - the plana lower, upper, and undivided units $\left(\mathrm{Hp}_{1}, A H \mathrm{p}_{2}\right.$, and $A \mathrm{Hp}_{\mathrm{u}}$, respectively) - are characterized by differing degrees of subparallel ridges, aligned or distributed knobs, and smooth depressions.

The interplana units group is found within the interplana trough. The interplana hummocky unit (Nih) crops out on the southwestern margin of Zephyria Planum and across the northern end of Aeolis Dorsa where it forms a broad (tens of km wide), rounded, topographic high, adjacent to Zephyria Planum on its eastern end. The interplana mounds unit (Him) crops out as $10-\mathrm{km}$-scale scattered mounds and outcrops between or on the margins of the plana.

The Aeolis Dorsa units group is named relative to the individual and networked sinuous ridges (dorsa) that characterize them. This group consists of lower $\left(\mathrm{Had}_{1}\right)$, middle $\left(\mathrm{Had}_{2}\right)$, upper $\left(\mathrm{AHad}_{3}\right)$, and Aeolis Dorsa undivided units $\left(\mathrm{Had}_{4}\right)$. 
The crater units group consists of units formed directly or indirectly by impact cratering. The crater unit $(\mathrm{AHc})$ is found throughout the map area, although concentrated numerically within the interplana region. The crater fill unit (Hcf) is found within several craters in the interplana region.

The label for each mapped unit begins with a letter in capital form identifying the chronologic period. These periods and their boundary ages according to Michael (2013), which is based on work by Hartmann and Neukum (Hartman and Neukum, 2001; Hartman, 2005; see also Ivanov, 2001), are N, Noachian, >3.71 Ga (Neukum system) or $>3.56 \mathrm{Ga}$ (Hartmann, 2005); H, Hesperian, 3.71-3.37 Ga (Neukum system) or 3.56-3.24 Ga (Hartmann, 2005); and A, Amazonian, 3.37-0 Ga (Neukum system) or 3.24-0 Ga (Hartmann, 2005). Next in the label is indicated the unit group (h, highlands; t, transitional; p, plana; i, interplana; ad, Aeolis Dorsa; c, crater) and the unit within that group. Lastly, a descriptor letter in subscript form may be used to identify stratigraphic relations (for example, 1 , lower; $\mathrm{u}$, undivided).

\section{Contact Types}

Unit exposures were delineated using contact types and symbology from the FGDC Digital Cartographic Standard available in ArcGIS software supplied by the USGS Astrogeology Science Center Planetary Geologic Mapping Group. The different contact types indicate the level of certainty we attribute to our delineations. These types are (1) certain, which denotes a clearly discerned contact location between two distinct exposures that differ in characteristics and (or) interpreted relative age, and (2) approximate, used where the location of the contact is less clearly discerned, whether by data quality or geologic obscuration. The symbology for an approximate contact is also used where the location of the contact is uncertain and (or) gradational.

\section{Feature Types}

Following precedents established in previous terrestrial and planetary geologic maps, we use a variety of groups of morphologic feature symbols that are subdivided into more specific feature types. Feature types consist of symbology from the FGDC Digital Cartographic Standard for Geologic Map Symbolization (2006) in ArcGIS software supplied by the USGS Astrogeology Science Center Planetary Geologic Mapping Group.

\section{Location Feature}

We mapped a single location feature, namely, craters with diameters less than $1 \mathrm{~km}$. These subkilometer craterforms exhibit central depressions and may or may not be elevated above the surrounding terrain. Some subkilometer craters on the plana have been eroded into knobs (Kerber and Head, 2010), but because knobs could also be formed by other processes, they were not included in the mapping of subkilometer craterforms. Such small craters are easily obscured by surface modification even in the Amazonian (Werner and Tanaka, 2011), as shown by rollover in crater populations at small sizes in Athabasca Valles, located to the north of the map area (for example, Burr and others, 2002). For these reasons, the mapped subkilometer crater population, which provides a representation of the relative number of craters per unit outcrop, provides a minimum or lower limit on the number of these smallest craters in the study area. These smallest craters are considered to be larger than about $15 \mathrm{~m}$ in diameter on the basis of the CTX base map resolution.

Compared to other units, unit Hpc shows a high density of these small craters ( 0.87 craters per $\mathrm{km})$, suggesting high crater retention. However, the virtual lack of any larger craters and the superposition on the cratered plains of a few plana outcrops indicates burial and recent exposure, as previously inferred for the MFF (for example, Kerber and Head, 2010). The large exposures of unit AHc also show high densities of small craters, as do the highland units (Nhp and HNhm) in the southern portion of the map, significant parts of the transitional units ( $\mathrm{HNtt}$ and $\mathrm{Ht}_{\mathrm{u}}$ ), and some parts of some outcrops of the Aeolis Dorsa units $\left(\mathrm{Had}_{1}, \mathrm{Had}_{2}, \mathrm{AHad}_{3}\right.$, and $\left.\mathrm{Had}_{4}\right)$. A limited number of linear crater clusters crosscut multiple units.

\section{Linear Features}

The group of linear features includes nine different types. Features attributed as "channel (fluvial)," shown as dashed blue lines, are negative relief sinuous troughs less than $1 \mathrm{~km}$ in width and as much as $10 \mathrm{~km}$ in length. They are preferentially located on the Aeolis Dorsa units $\mathrm{Had}_{1}$ and $\mathrm{Had}_{2}$ and are also found on the interplana mounds unit Him. We mapped 35 channels within the map region ranging in length from 1.4 to $8.8 \mathrm{~km}$.

We mapped two types of ridges, distinguished by their morphology. Wrinkle ridges (fig. $2 A$ ) are characterized by crenulated narrow ridges on top of broader linear features with angular bends or en echelon morphology (see references in Borden, 2018). They have asymmetric topography in profile, although the sense of that asymmetry can change along strike. In our map area, these wrinkle ridges are smaller in size (about 2 to $46 \mathrm{~km}$ in length) than similar features seen elsewhere on Mars. Although their visual expressions are commonly only on the order of about $1 \mathrm{~km}$ in width, topographic data show that the broad rise that characterizes these features elsewhere on Mars (for example, Golombek and others, 2001) is also present here as wide as about $18 \mathrm{~km}$. In the map region, wrinkle ridges exhibit predominantly north-south orientations with an azimuth of about $80^{\circ}$ and are widely scattered, not exhibiting preferential clustering in any map unit (Borden, 2018). We mapped 35 wrinkle ridges in the map area on the basis of 6 characteristics from the published literature that consisted of a topographic rise, asymmetry, a narrow ridge, subparallel and overlapping segments, a curvilinear shape, and a broad basal arch. Features identified as "wrinkle ridge, certain" exhibit 5 of these 6 characteristics, whereas features identified as "wrinkle ridge, approx." exhibit 3 or 4 of these characteristics. Wrinkle ridges are interpreted to form through tectonic contraction (Borden, 2018, and numerous references therein).

Sinuous ridges (fig. $2 B$ ) are linear features that are generally larger than wrinkle ridges and are as wide as a few $\mathrm{km}$ and extend several tens of $\mathrm{km}$ in length; the longest 
example, Aeolis Serpens, stretches more than $450 \mathrm{~km}$ across the map area. Many of these ridges exhibit about 2-km-wide plan forms having more sinuous morphologies than the wrinkle ridges, sometimes with fine-scale, semi-arcuate lineations on their surfaces. A smaller number of sinuous ridges, generally occurring in radial clusters, exhibit straighter and more narrow morphologies without the subparallel segmentation of the wrinkle ridges. The smallest number of these ridges exhibit the lowest sinuosities and sometimes form fan shapes, connecting at and diverging from a single location. These sinuous ridge morphologies have been interpreted as inverted water-lain deposits (Burr and others, 2009, 2010; Lefort and others, 2012; Williams and others, 2013; Kite and others, 2015a; Jacobsen and Burr, 2017). Inverted fluvial deposits form by induration of the fluvial sediments followed by preferential removal of the less-indurated surrounding landscape (for example, Jacobsen and Burr, 2017, and multiple references therein). The broadest and most numerous inverted deposits with surface lineations are interpreted as scroll bars of ancient meandering rivers (Hughes and others, 2019), whereas those without surface lineations are interpreted as channel fill (Kite and others, 2015a; Jacobsen and Burr, 2017). The narrower sinuous ridges are also interpreted as channel fill, and the straightest morphologies have been interpreted regionally as inverted alluvial fan channels (Burr and others, 2009; Kite and others, 2015a; Jacobsen and Burr, 2017). Some of these deposits around the southwestern and southern margin of Aeolis Dorsa have been interpreted as deltaic (DiBiase and others, 2013; Hughes and others, 2019). The inverted fluvial deposits have been grouped into these four morphologic categories - thin, flat, fan, and Aeolis Serpens (as shown in Jacobsen and Burr, 2017, their fig. 9) - and those categorized delineations are included with the electronic map (“Aeolis-Dorsa-delineations_Jacobsen\&Burr-2017”).

These inverted water-lain deposits are commonly located around the interior margins of the two plana and are oriented roughly radially to the interplana trough, the salient exception being Aeolis Serpens (fig. 1), which is located approximately along the interplana trough centerline (colocated with the $\mathrm{Had}_{2}$ unit between lat $-5.5^{\circ} \mathrm{N}$. and northern extent of the map area at the equator). Previous (non-USGS) mapping delineated and described three morphologies for these inverted fluvial deposits and provided their stratigraphy in four locations within the map area (Jacobsen and Burr, 2017). These stratigraphies show that the inferred meandering river or deltaic (Hughes and others, 2019) deposits formed at the lowest stratigraphic level, superposed by non-meandering channel fill deposits or in some locations by the alluvial fans and (or) a deltaic deposit in the southeastern map area (DiBiase and others, 2013). Although previous work has mapped multiple morphologies, a single symbology is used on the map sheet for simplicity and map legibility to represent all inverted fluvial and alluvial ridges. The symbols include both "certain" and "approx." denominations to indicate whether the sinuous features are qualitatively more continuous or discontinuous along their lengths.

We designated two types of crater rims. The crests of crater rims are mapped when appearances indicate the presence of relief on either one or both sides, and the symbology for crests of buried craters is used where roughly circular features are visible but relief is not apparent. Small crater rims are mapped for craters between 1 and $4 \mathrm{~km}$ in diameter. Craters smaller than $1 \mathrm{~km}$ in diameter are mapped as previously described under the "Location Feature" section.

We mapped the margins of depressions where the apparent depressions are greater than about10 km along their longest axes. The nine mapped depression margins are most commonly found on plana units, with one example on the crater ejecta unit. The margin of the depression that hosts the transitional chaos terrain unit (Htct) is shown by the outline of the unit and is not mapped using the linear feature symbology for "depression margin."

A scarp crest is used to designate the upper topographic inflection from a more horizontal to a more vertical slope of a linear to curvilinear, step-like feature. Most of the scarp crests are located within unit AHc where they represent the top of steep-sided ejecta margins. Along the interior (southwest) side of Zephyria Planum, a series of subparallel topographic steps are represented with scarp crest symbology, which, because of the close spacing of the scarps, is applied to every other scarp to be consistent with the map scale. These features are visible within the crater unit (AHc) and less distinctly with the contiguous plana lower unit $\mathrm{Hp}_{1}$. Scarp crests were also not mapped around the outside of crater ejecta (unit AHc) in contact with other units because the geologic contacts at those locations indicate those changes in slope.

Grooves are mapped to highlight clusters of narrow, arcuate, subparallel depressions that have a spacing on the order of $1 \mathrm{~km}$. Two clusters are found, one in the broad northern exposure of unit Nih and one at the northern edge of the map in the plana undivided unit $\left(\mathrm{AHp}_{\mathrm{u}}\right)$.

The symbology for these features is provided in the "Explanation of Map Symbols" section. Consistent mapping across all geologic units was challenging because of variations in geology (for example, unit preservation and [or] degree of erosion) and in data quality (for example, illumination angle). However, comprehensive mapping of every feature in some locations yielded an overcrowded and poorly legible map. Our delineation of features on the map is designed to provide a realistic cartographic representation rather than exact indicators of spatial location and abundance.

\section{Digital Drafting Parameters}

We used the Esri, Inc., ArcGIS software (v. 10.3 through 10.5 ) to analyze available datasets. We digitized points, lines, and polygons either by placing each vertex individually or with the digital streaming capability in ArcGIS. We digitized vector linework at a consistent scale of 1:100,000, or 500 percent of the publication map scale of 1:500,000. Vertex spacing was set to place points within linework at 400 meters during streaming, although not all mappers used streaming throughout. Smoothing threshold was added upon acceptance.

Initial linework and (or) feature mapping was accomplished iteratively by all mappers using desktop computers on individual copies of the USGS-supplied ArcGIS data package, which included location, surface, and linear feature types, geocontact types, the CTX base map, and THEMIS and MOLA mosaics. The mapping was done on 
spacecraft data in Equidistant Cylindrical projection (center longitude of $0^{\circ} \mathrm{E}$.). Contact linework was cleaned (for example, topology was run and dangles removed), converted to unit polygons, and attributed with geologic units, then compiled with point and linear features. The resultant draft map was reviewed by Devon Burr and Robert Jacobsen and revised using a WACOM digital mapping tablet. This internal review, including comparison across datasets and among mappers, enabled refinement of contact placement, geologic unit descriptions and outcrop unit attribution. To balance the detailed mapping potential of the high-resolution base map with the need for clear and consistent cartographic representation both in print and electronically, all unit outcrops are larger than $1 \mathrm{~km}^{2}$ and linear features are longer than $1 \mathrm{~km}$ or a lower limit of two millimeters at map scale.

\section{Age Determinations}

The assignment of an Amazonian age to the MFF was based on the paucity of superposing craters (Tanaka, 1986). However, subsequent research has shown that preserved craters in the Aeolis Dorsa region indicate western MFF emplacement by at least the Late Hesperian (Zimbelman and Scheidt, 2012), consistent with ages derived from an analysis of relative stratigraphic relationships for the entire MFF (Kerber and Head, 2010). This previous work demonstrates the significant uncertainty associated with ages derived from crater densities in this region, given the highly erosive nature of the landscape (Ward, 1978; Mandt and others, 2009; Zimbelman and Griffin, 2010).

For this reason, age determinations in the map area are based on relative adjacency and stratigraphic relations (for example, superposition and crosscutting relations) as evidence for the sequence of unit emplacement and modification rather than crater size frequency distributions. This sequence is tied to the global time-stratigraphic record of Mars (for example, Tanaka, 1986; Werner and Tanaka, 2011). Map unit assignments to Martian epochs within this global framework are founded on assignment by previous workers of the southern highlands units (for example, Tanaka and other, 2014) immediately south of the map area to the Noachian and extrapolated therefrom.

The highlands units are collectively interpreted as the oldest units in the map area. In the southwest corner of the map area, unit Nhp is exposed in locations attributed to the Noachian Period by Tanaka and others (2014) and is here assigned to the Middle Noachian Epoch. The high density of small impact craters on the unit is consistent with this inferred ancient age. Unit $\mathrm{HNh}_{\mathrm{u}}$, everywhere adjacent to the plateau unit, overlies and so postdates unit Nhp and is interpreted to have developed throughout the Middle Noachian to Early Hesperian. Unit HNhm, proximal to unit Nhp and commonly adjacent to unit $\mathrm{HNh}_{u}$, has characteristics of terrains and so is assigned a younger age of Late Noachian to Early Hesperian.

The oldest transitional unit, unit HNtt, occurs adjacent to and north of unit HNhm. Unit HNtt is exposed as rough highstanding surfaces of mesas and cuspate ridges and is interpreted as highlands detritus that was shed, indurated, and abraded. Unit HNtt is ascribed to have developed contemporaneously with other units of Late Noachian to Early Hesperian age. Unit $\mathrm{Ht}_{\mathrm{u}}$ fills in around, and so postdates, the highland mesas and is ascribed to the Early Hesperian. Unit Htct contains isolated mesas of unit HNhm and is interpreted on the basis of its elevation and geographic context to be tectonically extended highlands. We ascribe unit Htct to the Middle Hesperian because cross-cutting relationships indicate it formed after unit $\mathrm{HNhm}$. The termination of fluvial features in unit $\mathrm{Had}_{1}$ at the edge of the depression unit (Htct) corroborates the extension occurring after emplacement of that Early Hesperian Htct unit.

The other units ascribed to the Noachian are in the plana and interplana units. Of the plana units, unit Npm shows surface textures similar to those on the Nhp unit, and unit Npm is ascribed an age following the emplacement of the highlands Npm unit during the Middle Noachian. Unit Nih, located on the margins of Zephyria Plana and in northern Aeolis Dorsa, is distal to the plana mesas (Npm) and highlands plateau (Nhp) units, so it exhibits no direct stratigraphic relationships with these older units. It does exhibit direct stratigraphic relations with the surrounding Aeolis Dorsa units $\mathrm{Had}_{4}, \mathrm{Had}_{1}$, and $\mathrm{Had}_{2}$, which are ascribed to the Early Hesperian as explained below. We therefore ascribe this unit to the Late Noachian.

Unit Him, characterized by mounds, seems to superpose the older Aeolis Dorsa units $\mathrm{Had}_{1}$ and $\mathrm{Had}_{2}$, while being crosscut by unit $\mathrm{AHad}_{3}$ in the southeastern map area. Thus, we assign Him an age of middle Late Hesperian.

The remaining plana units exhibit variable degrees of aeolian abrasion in the form of yardangs. The $\mathrm{Hp}_{1}$ unit fills in and surrounds highlands mesas of Late Noachian to Early Hesperian age where it is apparently interleaved with the $\mathrm{HNh}_{\mathrm{u}}$ unit, so is ascribed an age of Early Hesperian. The $\mathrm{AHp}_{2}$ unit forms at higher elevations than the $\mathrm{Hp}_{1}$ unit, and its yardangs crosscut those in the $\mathrm{Hp}_{1}$ unit, indicating a younger age for this superposed unit (as shown in fig. 3). Unit AHpu incorporated terrain with similar attributes to units $\mathrm{Hp}_{1}$ and $A \mathrm{Hp}_{2}$, and the contacts and relative stratigraphic relationships are unclear, causing us to assign a broad, Early Hesperian to Early Amazonian age.

The Aeolis Dorsa units have been previously mapped and their relative stratigraphic positions inferred (Kite and others, 2015a; Jacobsen and Burr, 2017). This previous work shows that unit $\mathrm{Had}_{1}$, which displays broad, lineated ridges, is superposed by unit $\mathrm{Had}_{2}$, which consists of thinner (narrow) and (or) nonlineated ridges (fig. 4) and unit $\mathrm{AHad}_{3}$, which displays bifurcating ridges. Here, we also map unit $\mathrm{Had}_{u}$ as undivided terrain with a fluvial texture that could not be clearly ascribed to any of the other three units. We ascribe these relative superposition relations to the Hesperian on the basis of the superjacent relation of the stratigraphically lowest unit, $\mathrm{Had}_{1}$, with the Noachian to Hesperian transition unit HNtt. Support for an Early Hesperian age to these visible fluvial and alluvial deposits (see the "Introduction" and "Unit Groups, Names, and Labels" sections above) is the detection of a fluviatile unit in the shallow subsurface in the mosaic of THEMIS night infrared data (fig. 5; Burr and others, 2016). A most likely formation age for this buried fluvial unit at the Noachian to Hesperian climatic optimum would imply an Early Hesperian age for these superposed visible units. 
The moderate size and surprisingly good preservation of craters in this region suggest that they postdate the Noachian. We ascribe the oldest craters (unit AHc) to the Early Hesperian, consistent with Tanaka and others (2014). Mapping intercrater deposits that are distinct from generic aeolian infill shows that these outcrops of the unit Hcf are found in the largest several craters within Aeolis Dorsa. On the basis of an inferred maximum age of Early Hesperian for these craters and the assumed increasing predominance of aeolian deposition in the Middle to Late Amazonian, we ascribe a Hesperian age to these crater fills. Unit Hpc crops out in the northwest and northeast corners of the map area, adjacent to the Cerberus lava plains, as smooth, cratered plains. Within the map area, these plains are hypothesized to have been emplaced during the Hesperian on the basis of prior mapping of Late Hesperian lavas in the northeastern map area (Tanaka and others, 2014) and the embayment of the Hesperian MFF by these lavas (Kerber and Head, 2010).

\section{Geologic Summary}

In this section, we summarize the geologic history of the Aeolis Dorsa region as derived from the geologic unit and landform mapping and age determinations given above. This summary is shown pictorially in the accompanying Correlation of Map Units.

\section{Noachian Period}

On the basis of this mapping, the recorded geologic history of the Aeolis Dorsa region begins in the Middle Noachian during which unit Nhp was emplaced. Based on interpretations of global highlands terrain by Tanaka and others (2014, pl. $1)$, the highlands terrains in the Aeolis Dorsa map area likely represent "undifferentiated friable sedimentary, impact, and volcanic materials." Broad linear grooves in this unit indicate extension, whereas scattered wrinkle ridges point to localized contraction. Mesas with semi-rectilinear planforms and similar surface textures as the highlands plateaus (unit Npm) occur on Aeolis Plana and are interpreted as distal plateau outcrops. Even farther north, hummocky terrain of unit Nih forms a topographic barrier a few hundred meters in height across the broad interplana trough. Possible origins of this unit, which is also mapped along interior (western) Zephyria Plana, include extensively modified highlands material.

\section{Hesperian Period}

In the Late Noachian and into the Hesperian, the southernmost exposure of unit Nhp was altered to form the proximal unit HNhm. This weathering also generated unit $\mathrm{HNh}_{\mathrm{u}}$, which occurs as talus slopes around the margins of unit Nhp. Weathering, longer-distance transport, and emplacement of plateau materials led to formation of unit HNtt and subsequently of unit $\mathrm{Ht}_{\mathrm{u}}$. The chaotic morphology of unit Htct along with its approximate kilometer of negative relief indicates its formation from collapse. This collapse might have been caused by loss of volatiles, which are a possible component of the MFF as suggested by geomorphology (McColley and others, $2005)$, by the potential of volatiles in the circum-Cerberus deposits (Keszthelyi and others, 2000), and by modeling of the nearby Gale crater mound (Kite and others, 2013). Alternatively, or in addition, the inference of fluvial slope reversal in the southern Aeolis Dorsa region, combined with geophysical modeling, indicates the influence in this map subregion of tectonic extension caused by erosion of highlands materials to the south and deposition of the MFF to the north (Lefort and others, 2015). Tectonic extension in the Aeolis Dorsa region is consistent with inferred extension for the Nepenthes Mensae terrain to the west (Tanaka and others, 2005).

Repeated sedimentation and erosion by interleaved aeolian and fluvial activity occurred throughout the Hesperian Period. Unit $\mathrm{Had}_{1}$ represents the earliest fluvial deposits, emplaced by meandering rivers, that may have terminated in deltas in the southeastern area of the map (Hughes and others, 2019). However, erosion of this unit (as shown near lat $-6.2^{\circ} \mathrm{N}$., long $151.2^{\circ}$ E. or lat $-3.8^{\circ} \mathrm{N}$., long $153.3^{\circ}$ E.) shows a subjacent abraded aeolian unit $\left(\mathrm{AHp}_{\mathrm{u}}\right.$; fig. 6), which implies one or more prefluvial aeolian events that entailed sediment deposition, subsequent induration, aeolian erosion, and burial by the fluvial unit. A second episode of fluvial sedimentation is recorded in unit $\mathrm{Had}_{2}$ and is observed to crosscut unit $\mathrm{Had}_{1}$ in the southcentral map area (near lat $-5.7^{\circ} \mathrm{N}$., long $153.5^{\circ} \mathrm{E}$.; fig. 4). Unit $\mathrm{AHp}_{2}$ is also ascribed to Late Hesperian time on the basis of its general higher elevation and observed crosscutting relations (as shown near lat $-0.1^{\circ} \mathrm{N}$., long $153.15^{\circ} \mathrm{E}$.) with the unit $\mathrm{Hp}_{1}$. The Aeolis Dorsa upper unit $\left(\mathrm{AHad}_{3}\right)$ is expressed as alluvial fans that are observed to directly superpose the first Aeolis Dorsa unit along the interior southwest margin of Zephyria Plana (as shown on map sheet near lat $-4.8^{\circ} \mathrm{N}$., long $154.8^{\circ} \mathrm{E}$.). Deltaic processes are suggested by interpretation of a limited number of these $\mathrm{AHad}_{3}$ deposits that have deltaic planforms, context, and stratigraphy (DiBiase and others, 2013). This interpretation would imply flow reversal during the Hesperian from the outward or southeastward flow of the inferred deltaic deposits to the generally inward flow into the interplana trough of the inferred alluvial fans that postdate the deltaic deposits.

Unit $\mathrm{Had}_{\mathrm{u}}$, whose stratigraphic relation with the other Aeolis Dorsa units cannot be determined, is ascribed to the Hesperian and is underlain by the thermally distinct area that appears brighter in the nighttime THEMIS infrared data (fig. 5). We interpret this underlying area to be fluvially emplaced on the basis of its elongate sinuous branches that join a centralized topographically low basin. The greater areal extent of the superjacent unit $\mathrm{Had}_{\mathrm{u}}$, which reveals the less extensive thermally distinct areas in some locations, suggests that the later fluvial activity of the superjacent $\mathrm{Had}_{u}$ unit was sufficient to erode the basin margins outward to their current location.

Unit Him, stratigraphically interleaved with Aeolis Dorsa units, is interpreted as remnants of plana that are emplaced by regional-scale depositional process(es) and then modified by Late Hesperian fluvial and aeolian activity.

Impact cratering, which was not well recorded during the Noachian, continued during the Hesperian as indicated by the 
temporal occurrence of unit AHc. Some of these craters hosted fluvial and (or) lacustrine processes, which are reflected in unit Hcf. Effusive volcanism occurred in the northwest and northeast corners of the map area (unit Hpc), as indicated by terrain with good crater retention, low albedo and planar morphology. These unit Hpc outcrops might provide exposures of the extensive lava flow inferred from radar to underlie the plana (Watters and others, 2007; Jacobsen and Burr, 2017). Superposed plana deposits on outcrops of unit Hpc, which we interpret as outcrops of lava flows, demonstrate that their crater population reflects an exposure age.

The occurrence of 10-km-long wrinkle ridges in Hesperian units indicate localized contraction after emplacement of these units. Larger-scale wrinkle ridges on the order of 100 $\mathrm{km}$ characterize the global Hesperian to Noachian transition unit (HNtt) to the east and west of the map region and are attributed to crustal tectonism (Tanaka and others, 2014). The smaller wrinkle ridges in the Aeolis Dorsa region may be due to strength contrasts between stratal layers, perhaps because of ice- or clay-rich layers, although a regional cause for the contraction is not yet known (see Borden, 2018, for further discussion). More contraction might have occurred than is indicated by the exposed wrinkle ridges because any ridges in the interplana region would have been covered by fluvial sediments. Local extension occurred along the interior southern margin of Zephyria Planum, as indicated by small-scale scarps and perhaps resulting from removal of buttressing materials by the fluvial processes represented by the Aeolis Dorsa units.

\section{References Cited}

Banerdt, W.B., and Russell, C.T., 2017, Editorial on; topical collection on InSight Mission to Mars: Space Science Reviews, v. 211, no. 1-4, p. 1-3. [Also available at https://doi.org/10.1007/ s11214-017-0414-0.]

Banerdt, W.B., Smrekar, S., Hoffman, T., and 36 others, 2017, The InSight mission for 2018: Lunar and Planetary Science Conference XLVII, abstract 1896. [Also available at https://www.hou. usra.edu/meetings/lpsc2017/pdf/1896.pdf.]

Beyer, R.A., Alexandrov, O., and McMichael, S., 2018, The Ames Stereo Pipeline-NASA's open source software for deriving and processing terrain data: Earth and Space Science, v. 5, p. 53-548. [Also available at https://doi. org/10.1029/2018EA000409.]

Borden, R.M., 2018, Mapping and analysis of wrinkle ridges in the Aeolis Dorsa region, Mars; Implications for stress fields and geologic substrates: Knoxville, Tennessee, University of Tennessee, Master's thesis, $41 \mathrm{p}$.

Burr, D.M., Enga, M.-T., Williams, R.M.E., Zimbelman, J.R., Howard, A.D., and Brennand, T.A., 2009, Pervasive aqueous paleoflow features in the Aeolis/Zephyria Plana region, Mars: Icarus, v. 200, p. 52-76. [Also available at https://doi. org/10.1016/j.icarus.2008.10.014.]

Burr, D.M., Grier, J.A., McEwen, A.S., and Keszthelyi, L.P., 2003, Repeated aqueous flooding from the Cerberus Fossae: Evidence for Very Recently Extant, Deep Groundwater on Mars: Icarus,

\section{Amazonian Period}

Some of the geologic units that originated in the Hesperian Period continued to be emplaced or modified during the Early Amazonian, including the fluvial activity of unit $\mathrm{AHad}_{3}$ and impact cratering reflected in unit AHc. Aeolian activity is indicated by the plana units $\mathrm{AHp}_{2}$ and $\mathrm{AHpu}$, which show very sparse crater densities that suggest recent or ongoing modification by aeolian erosion. Depressions on Zephyria and (to a lesser extent) Aeolis Plana with few or no impact craters suggest very recent or ongoing aeolian deflation.

\section{Acknowledgments}

Creating this map was accomplished by a sequence of steps not dissimilar to the geologic processes that occurred in the map area, involving repeated deposition of lines, followed most commonly by erasure, to be redeposited and likely re-erased again. We thank the U.S. Geological Survey Astrogeology Map Planetary Geologic Map Coordination Group for their continual assistance and willing (sometimes repeated) instruction on the mapping technology, as well as their experienced input on the science. Sharon Wilson and Lauren Edgar provided constructive and helpful critique. This work was accomplished with funding support from the National Aeronautics and Space Administration Mars Data Analysis Program [NNX14AM03G] and Graduate Assistantships from the University of Tennessee to REJ, RMB, and SEP.

v. 159, p. 53-73. [Also available at https://doi.org/10.1006/ icar.2002.6921.]

Burr, D.M., Jacobsen, R.E., and Lefort, A., 2016, Thermal detection of an extensive buried fluvial unit in the Aeolis Dorsa region, Medusae Fossae Formation, Mars [abs.], in $47^{\text {th }}$ Lunar and Planetary Science Conference, The Woodlands, Tex., March 21-25, 2016, abstract 1392. [Also available at https:// www.hou.usra.edu/meetings/lpsc2016/pdf/1392.pdf.]

Burr, D.M., Jacobsen, R.E., Lefort, A., and Peel, S.E., 2019, The climate history of Mars encapsulated in the Aeolis Dorsa region [abs.]: Geologic Society of America Abstracts with Programs, v. 51, no. 5, paper no. 86-3. [Also available at https://gsa.confex. com/gsa/2019AM/webprogram/Paper334650.html.]

Burr, D.M., Williams, R.M.E., Wendell, K.D., Chojnacki, M., and Emery, J.P., 2010, Inverted fluvial features in the Aeolis/ Zephyria Plana region, Mars-Formation mechanism and initial paleodischarge estimates: Journal of Geophysical Research, v. 115, no. E7, 20 p. [Also available at https://doi. org/10.1029/2009JE003496.]

Cardenas, B.T., Mohrig, D., and Goudge, T.A., 2017, Fluvial stratigraphy of valley fills at Aeolis Dorsa, Mars - Evidence for base-level fluctuations controlled by a downstream water body: Geological Society of America Bulletin, v. 130, no. 3-4, p. 484 498. [Also available at https://doi.org/10.1130/B31567.1.]

Carr, M.H., and Head, J.W., III, 2010, Geologic history of Mars: Earth and Planetary Science Letters, v. 294, No. 3-4, p. 185-203. [Also available at https://doi.org/10.1016/j.epsl.2009.06.042.] 
Christensen, P.R., Jakosky, B.M., Kieffer, H.H., Malin, M.C., McSween, H.Y., Nealson, K., Mehall, G.L., Silverman, S.H., Ferry, S., Caplinger, M., and Ravine, M., 2004, The Thermal Emission Imaging System (THEMIS) for the Mars 2001 Odyssey Mission: Space Science Reviews, v. 110, p. 85-130.

Di Achille, G., and Hynek, B.M., 2010, Ancient ocean on Mars supported by global distribution of deltas and valleys: Nature Geoscience, v. 3, p. 459-463. [Also available at https://doi. org/10.1038/NGEO891.]

DiBiase, R.A., Limaye, A.B., Scheingross, J.S., Fischer, W.W., and Lamb, M.P., 2013, Deltaic deposits at the Aeolis Dorsa-Sedimentary evidence for a standing body of water on the northern plains of Mars: Journal of Geophysical Research - Planets, v. 118, p. 1-18. [Also available at https://doi.org/10.1002/ jgre.20100.]

Dickson, J.L., Kerber, L.A., Fasset, C.I. and Ehlmann, B.L., 2018, A global, blended CTX mosaic of Mars with vectorized seam mapping: A new mosaicking pipeline using principles of nondestructive image editing [abs.], in 49th Lunar and Planetary Science Conference, The Woodlands, Tex., March 19-23, 2018, abstract 2480. [Also available at https:/www.hou.usra.edu/ meetings/lpsc2018/pdf/2480.pdf.]

Federal Geographic Data Committee [prepared for the Federal Geographic Data Committee by the U.S. Geological Survey], 2006, FGDC Digital cartographic standard for geologic map symbolization: Reston, Va., Federal Geographic Data Committee Document Number FGDC-STD_013-2006, 290 p., 2 plates.

Fergason, R.L., Lee, E.M., and Weller, L., 2013, THEMIS geodetically controlled mosaics of Mars [abs.], in 44th Lunar and Planetary Science Conference, The Woodlands, Tex., March 18-22, 2013, abstract 1642. [Also available at https:/www.lpi. usra.edu/meetings/lpsc2013/pdf/1642.pdf.]

Fergason R.L., and Weller L., 2018, The importance of geodetically controlled data sets - THEMIS controlled mosaics of Mars, a case study [abs.], in Planetary Science Informatics and Data Analytics Conference, St. Louis, Mo., April 24-26, 2018, abstract 6030, LPI Contribution no. 2082. [Also available at https://www. hou.usra.edu/meetings/informatics2018/pdf/6030.pdf.]

Golombek, M.P., Anderson, F.S., and Zuber, M.T., 2001, Martian wrinkle ridge topography: Evidence for subsurface faults from MOLA: Journal of Geophysical Research, v. 106, no. E10, p. 23811-23822. [Also available at https://doi. org/10.1029/2000JE001308.]

Greeley, R., and Batson, R.M., eds., 1990, Planetary mapping: New York, NY, Cambridge University Press, 296 p.

Greeley, R., and Guest, J.E., 1987, Geologic map of the eastern equatorial region of Mars: U.S. Geological Survey Geologic Investigations Series Map I-1802-B, scale 1:15,000,000. [Also available at https://doi.org/10.3133/i1802B.]

Grotzinger, J.P., Crisp, J., Vasavada, A.R., and 23 others, 2012, Mars Science Laboratory mission and science investigation: Space Science Reviews, v., 170, no. 1-4, p. 5-56. [Also available at https://doi.org/10.1007/s11214-012-9892-2.]

Harrison, S.K., Balme, M.H., Hagermann, A., Murray, J.B., Muller, J.-P., and Wilson, A., 2013, A branching, positive relief network in the middle member of the Medusae Fossae Formation, equatorial Mars - Evidence for sapping?: Planetary and
Space Science, v. 85, p. 142-163. [Also available at https://doi. org/10.1016/j.pss.2013.06.004.]

Hartmann, W.K., 2005, Martian cratering 8-Isochron refinement and the chronology of Mars: Icarus, v. 174, p. 294-320. [Also available at https://doi.org/10.1016/j.icarus.2004.11.023.]

Hartmann, W.K., and Berman, D.C., 2000, Elysium Planitia lava flows - Crater count chronology and geological implications: Journal of Geophysical Research - Planets, v. 105, no. E6, p. 15011-15026. [Also available at https://doi. org/10.1029/1999JE001189.]

Hartmann, W.K., and Neukum, G., 2001, Cratering chronology and the evolution of Mars: Space Science Reviews, v. 96, p. $165-194$.

Hughes, C.M., Cardenas, B.T., Goudge, T.A., and Mohrig, D., 2019, Deltaic deposits indicative of a paleo-coastline at Aeolis Dorsa, Mars: Icarus, v. 317, p. 442-453. [Also available at https://doi.org/10.1016/j.icarus.2018.08.009.]

International Astronomical Union Working Group for Planetary System Nomenclature, 2020, Gazetteer of Planetary Nomenclature: International Astronomical Union Working Group for Planetary System Nomenclature web page. [Also available at https://planetarynames.wr.usgs.gov.]

Irwin, R.P., and Watters, T.R., 2010, Geology of the Martian crustal dichotomy boundary-Age, modifications, and implications for modeling efforts: Journal of Geophysical ResearchPlanets, v. 115, no. E11, 21 p. [Also available at https://doi. org/10.1029/2010JE003658.]

Ivanov, B.A., 2001, Mars/Moon cratering rate ratio estimates: Space Science Reviews, v. 96, p. 87-104.

Jacobsen, R.E., and Burr, D.M., 2016, Greater contrast in Martian hydrological history from more accurate estimates of paleodischarge: Geophysical Research Letters, v. 43, no. 17, p. 8,903-8,911. [Also available at https://doi. org/10.1002/2016GL070535.]

Jacobsen, R.E., and Burr, D.M., 2017, Dichotomies in the fluvial and alluvial fan deposits of the Aeolis Dorsa, Mars-Implications for weathered sediment and paleoclimate: Geosphere, v. 13, no. 6, p. 2154-2168. [Also available at https://doi. org/10.1130/GES01330.1.]

Kerber, L., and Head, J.W., 2010, The age of the Medusae Fossae Formation-Evidence of Hesperian emplacement from crater morphology, stratigraphy, and ancient lava contacts: Icarus, v. 206, p. 669-684. [Also available at https://doi.org/10.1016/j. icarus.2009.10.001.]

Keszthelyi, L.P., McEwen, A.S., and Thordarson, T., 2000, Terrestrial analogs and thermal models for Martian flood lavas: Journal of Geophysical Research, v.105, no. E6, p. 15027-15049. [Also available at https://doi.org/10.1029/1999JE001191.]

Kite, E.S., Halvey, I., Kahre, M.A., Wolff, M.J., and Manga, M., 2013, Seasonal melting and the formation of sedimentary rocks on Mars, with predictions for the Gale crater mound: Icarus, v. 233, p. 181-210. [Also available at https://doi.org/10.1016/j. icarus.2012.11.034.]

Kite, E.S., Howard, A.D., Lucas, A.S., Armstrong, J.C., Aharonson, O., and Lamb, M.P., 2015a, Stratigraphy of Aeolis Dorsa, Mars - Stratigraphic context of the great river deposits: Icarus, v. 253, p. 223-242. [Also available at https://doi.org/10.1016/j. icarus.2015.03.007.] 
Kite, E.S., Howard, A.D., Lucas, A., and Lewis, K.W., 2015b, Resolving the era of river-forming climates on Mars using stratigraphic logs of river-deposit dimensions: Earth and Planetary Science Letters, v. 420, p. 55-65. [Also available at https://doi.org/10.1016/j.eps1.2015.03.019.]

Lefort, A., Burr, D.M., Beyer, R.A., and Howard, A.D., 2012, Inverted fluvial features in the Aeolis-Zephyria Plana, western Medusae Fossae Formation, Mars-Evidence for post-formation modification: Journal of Geophysical Research, v. 117, no. E3. [Also available at https://doi.org/10.1029/2011JE004008.]

Lefort, A., Burr, D.M., Nimmo, F., and Jacobsen, R.E., 2015, Channel slope reversal near the Martian dichotomy boundary-Testing tectonic hypotheses: Geomorphology, v. 240, no. 1, p. 121-136. [Also available at https://doi.org/10.1016/j. geomorph.2014.09.028.]

Malin, M.C., Bell, J.F., III, Cantor, B.A., and 11 others, 2007, Context Camera investigation on board the Mars Reconnaissance Orbiter: Journal of Geophysical Research, v. 112, no. 5, 25 p. [Also available at https://doi.org/10.1029/2006JE002808.]

Mandt, K., de Silva, S., Zimbleman, J.R., and Crown, D.A., 2008, Origin of the Medusae Fossae Formation, MarsInsights from a synoptic approach: Journal of Geophysical Research-Planets, v. 113, no. E12. [Also available at https:// doi.org/10.1029/2008JE003076.]

Mandt, K., de Silva, S., Zimbelman, J., and Wyrick, D., 2009, Distinct erosional progressions in the Medusae Fossae Formation, Mars, indicate contrasting environmental conditions: Icarus, v. 204, no. 2, p. 471-477. [Also available at https://doi. org/10.1016/j.icarus.2009.06.031.]

McColley, S.M., Head, J.W., III, Neukum, G., and the High resolution stereo camera (HRSC) team, 2005, The Medusae Fossae Formation-Geological characteristics and topographic and stratigraphic relationships of the lower member along southeastern Elysium Planitia [abs.], in 36th Lunar and Planetary Science Conference, League City, Tex., March 14-18, 2005, Abstract 1184, 2 p. [Also available at https://www.lpi.usra.edu/meetings/ lpsc2005/pdf/1184.pdf.]

McEwen, A.S., Eliason, E.M., Bergstron, J.W., and 12 others, 2007, Mars Reconnaissance Orbiter's high resolution imaging science experiments (HiRISE): Journal of Geophysical Research-Planets, v. 112, no. E5, 40 p. [Also available at https://doi.org/10.1029/2005JE002605.]

McGill, G.E., and Dimitriou, A.M., 1990, Origin of the Martian global dichotomy by crustal thinning in the Late Noachian or Early Hesperian: Journal of Geophysical Research, v. 95, p. 12595-12605. [Also available at https://doi.org/10.1029/ JB095iB08p12595.]

Michael, G.G., 2013, Planetary surface dating from crater sizefrequency distribution measurements-Multiple resurfacing episodes and differential isochron fitting: Icarus, v. 226, no. 1, p. 885-890. [Also available at https://doi.org/10.1016/j. icarus.2013.07.004.]

Moffitt, F.H., and Mikhail, E.M., 1980, Photogrammetry (3d ed.): New York, Harper \& Row, Inc., 648 p.

Scott, D.H., and Carr, M.H., 1978, Geologic map of Mars: U.S. Geological Survey Miscellaneous Investigations Series Map I-1083, 1 sheet, scale 1:25,000,000. [Also available at https:// doi.org/10.3133/i1083.]
Skinner, J.A., Jr., Huff, A.E, Fortezzo, C.M., Gaither, T.A., Hare, T.M., and Hunter, M.A., 2018, Planetary Geologic Mapping Protocol: U.S. Geological Survey Planetary Geologic Map Coordination Group, Astrogeology Science Center web page. [Also available at https://astropedia.astrogeology.usgs.gov/ alfresco/d/d/workspace/SpacesStore/01e32dcd-3072-4ac28e41-7cc5029bd2cf/PGM Protocol_March2018.pdf.]

Skinner, J.A., Jr., and Tanaka, K.L., 2018, Geologic map of the Nepenthes Planum region, Mars: U.S. Geological Survey Scientific Investigations Map 3389, pamphlet 11p., scale 1:1,506,000. [Also available at https://doi.org/10.3133/sim3389.]

Smith, D.E., Zuber, M.T., Frey, H.V., and 21 others, 2001, Mars Orbiter Laser Altimeter-Experiment summary after the first year of global mapping of Mars: Journal of Geophysical Research-Planets, v. 106, no. E10, p. 23689-23722. [Also available at https://doi.org/10.1029/2000JE001364.]

Tanaka, K.L., 1986, The stratigraphy of Mars: Journal of Geophysical Research — Solid Earth, v. 91, no. B13, p. E139-158. [Also available at https://doi.org/10.1029/JB091iB13p0E139.]

Tanaka, K.L., Chapman, M.G., and Scott, D.H., 1992, Geologic map of the Elysium region of Mars: U.S. Geological Survey Miscellaneous Investigations Series Map I-2147, 1 sheet, scale 1:5,000,000. [Also available at https://doi.org/10.3133/i2147.]

Tanaka, K.L., Skinner, J.A., Jr., Dohm, J.M., and 6 others, 2014, Geologic map of Mars: U.S. Geological Survey Scientific Investigations Series Map 3292, scale 1:20,000,000, pamphlet 43 p. [Also available at https://doi.org/10.3133/sim3292.]

Tanaka, K.L., Skinner, J.A., Jr., and Hare, T.M., 2005, Geologic map of the northern plains of Mars: U.S. Geological Survey Scientific Investigations Series Map 2888, 1 sheet, scale 1:15,000,000. [Also available at https://pubs.usgs.gov/ $\operatorname{sim} / 2005 / 2888 /$.

Ward, A.S., 1979, Yardangs on Mars_Evidence for recent wind erosion: Journal of Geophysical Research, v. 84, no. B14, p. 8147-8166.

Watters, T.R., Campbell, B., Carter, L., and 10 others, 2007, Radar sounding of the Medusae Fossae Formation Mars-Equatorial ice or dry, low-density deposits?: Science, v. 318, no. 5853, p. 1125-1128. [Also available at https://doi.org/10.1126/ science.1148112.]

Werner, S.C., and Tanaka, K.L., 2011, Redefinition of the craterdensity and absolute-age boundaries for the chronostratigraphic systems of Mars: Icarus, v. 215, no. 2, p. 603-607. [Also available at https://doi.org/10.1016/j.icarus.2011.07.024.]

Williams, R.M.E., Irwin, R.P., III, Burr, D.M., Harrison, T., and McClelland, P., 2013, Variability in Martian sinuous ridge form-Case study of Aeolis Serpens in the Aeolis Dorsa, Mars, and insight from the Mirackina paleoriver, South Australia: Icarus, v. 225, no. 1., p. 308-324. [Also available at https://doi. org/10.1016/j.icarus.2013.03.016.]

Zimbelman, J.R., and Griffin, L.J., 2010, HiRISE images of yardangs and sinuous ridges in the lower member of the Medusae Fossae Formation, Mars: Icarus, v. 205, no. 1, p. 198-210. [Also available at https://doi.org/10.1016/j.icarus.2009.04.003.]

Zimbelman, J.R., and Scheidt, S.P., 2012, Hesperian age for western Medusae Fossae Formation, Mars: Science, v. 336, no. 6089 , p. 1683. [Also available at https://doi.org/10.1126/science.1221094.] 